\title{
Fermi resonances in the vibrational spectrum of perfluoroethane
}

\section{O.S. Golubkova*, D.N. Shchepkin, V.V. Bertsev, P.K. Sergeev}

Physical Faculty, St. Petersburg State University, Peterhof, St. Petersburg 198504, Russian Federation

\section{H I G H L I G H T S}

- The Raman spectrum of liquid $\mathrm{C}_{2} \mathrm{~F}_{6}$ is presented.

- Data on six fundamental Raman

bands of $\mathrm{C}_{2} \mathrm{~F}_{6}$ are obtained.

- Fermi resonances of states

$v_{7} \sim\left(2 v_{8}\right) \sim\left(v_{6}+v_{11}\right)$ and $v_{1} \sim\left(2 v_{6}\right)$ are detected.

\section{G R A P H I C A L A B S T R A C T}

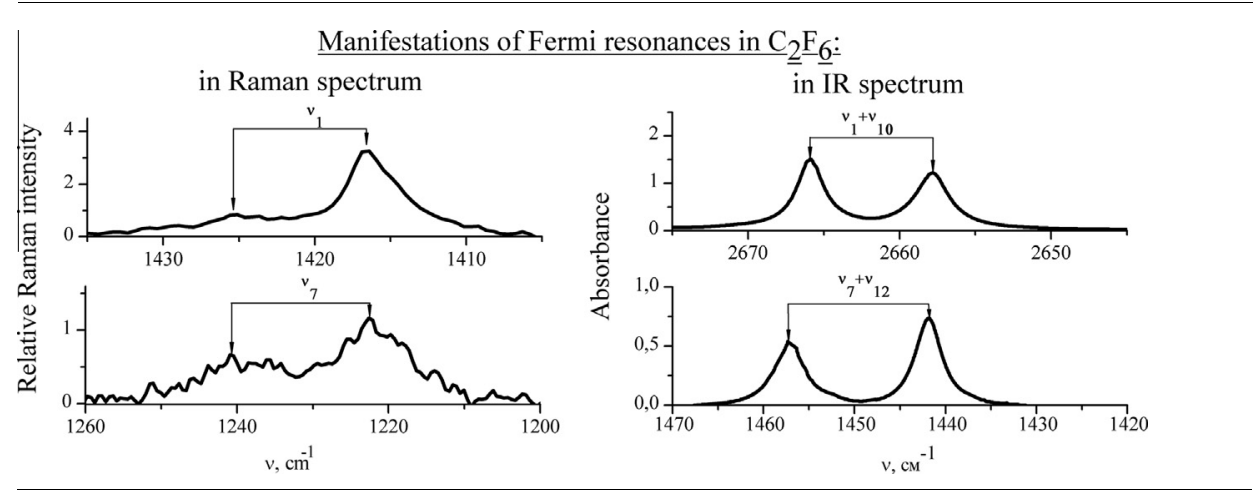

\section{A B S T R A C T}

In this paper the Raman spectrum of liquid $C_{2} F_{6}$ in the spectral region $250-1500 \mathrm{~cm}^{-1}$ is presented. Data on six fundamental Raman bands of $\mathrm{C}_{2} \mathrm{~F}_{6}$ are obtained. Doublets are observed in the spectral regions of the $v_{1}\left(A_{1 g}\right)\left(1416.3 \mathrm{~cm}^{-1}, 1425.0 \mathrm{~cm}^{-1}\right)$ and $v_{7}\left(E_{g}\right)\left(1221.9 \mathrm{~cm}^{-1}, 1239.7 \mathrm{~cm}^{-1}\right)$ fundamental bands. The structure of these bands is explained in terms of the Fermi resonances of $v_{7} \sim\left(2 v_{8}\right) \sim\left(v_{6}+v_{11}\right)$ $\left(E_{g}\right)$ and $v_{1} \sim\left(2 v_{6}\right)\left(A_{1 g}\right)$ states. The values of the cubic potential energy constant $K_{166}=7.7(2) \mathrm{cm}^{-1}$ and the effective matrix element of a threefold interaction $W_{\text {eff }}=8.5(5) \mathrm{cm}^{-1}$ were derived from the simultaneous processing of the doublet parameters in the Raman spectrum of liquid $\mathrm{C}_{2} \mathrm{~F}_{6}$ and in the IR spectrum of $\mathrm{C}_{2} \mathrm{~F}_{6}$ in liquid $\mathrm{N}_{2}$.

(c) 2015 Elsevier B.V. All rights reserved.
Keywords

Perfluoroethane

Cryosolutions

Raman spectra

Liquid

Fermi resonances

Cubic constants of potential energy

\section{Introduction}

Perfluoroethane $\mathrm{C}_{2} \mathrm{~F}_{6}$ is a greenhouse gas emitted into the atmosphere by semiconductor and aluminum industries $[1,2]$. In this connection optical properties of this molecule attract considerable interest. At present, the Raman spectrum of this molecule is not studied thoroughly. All modern researchers interested in the frequencies of Raman bands of the perfluoroethane molecule $\left(\mathrm{C}_{2} \mathrm{~F}_{6}\right)$ in the regions of fundamental transitions (for example, in order

\footnotetext{
* Corresponding author. Tel.: +7 812428 7419; fax: +7 8124286649

E-mail address: Olga.Golubkova@spbu.ru (O.S. Golubkova).
}

to estimate the results of ab initio calculation, for example $[3,4]$ ) refer to papers [5-7]. This data were obtained in the 1950-1970s.

Interpretation of Raman spectrum of gaseous $\mathrm{C}_{2} \mathrm{~F}_{6}$ in the fundamental spectral region is presented in [6]. The Raman spectrum of liquid $C_{2} F_{6}$ is studied in [5,7]. It is necessary to note that the main purpose of [7] was to study the vibrational spectrum of an $\alpha$-crystalline phase of perfluoroethane. In addition, the authors of [7] also reported the band frequencies of liquid $\mathrm{C}_{2} \mathrm{~F}_{6}$ but they did not present any spectra of the liquid and data on band intensities.

On the whole, the results of [5-7] are in satisfactory agreement with one another and until recently did not cause doubts. Note that manifestations of intramolecular resonances have not been 
observed in [5-7]. However, the presence of Fermi resonances of states $v_{1} \sim 2 v_{6}\left(A_{1 g}\right)$ and $v_{7} \sim 2 v_{8} \sim v_{6}+v_{11}\left(E_{g}\right)$ was recently predicted in paper [8]. According to [8], doublets and more complicated structures are observed in the IR spectrum of solution of $\mathrm{C}_{2} \mathrm{~F}_{6}$ in $\mathrm{Xe}(T=163 \mathrm{~K})$ in the spectral regions corresponding to vibrations combined with $v_{1}$ and $v_{7}$, which can only be interpreted with the resonance interactions taken into account. Therefore one can expect Fermi resonance multiplets $v_{1} \sim 2 v_{6}\left(A_{1 g}\right)$ and $v_{7} \sim 2 v_{8} \sim v_{6}+v_{11}\left(E_{g}\right)$ to appear in the Raman spectrum of $C_{2} F_{6}$ molecule.

The goals of this work are to measure the Raman frequencies in the spectrum of liquid $\mathrm{C}_{2} \mathrm{~F}_{6}$ more accurately, to determine their relative intensities, and to specify resonance characteristics of higher vibrational states using the IR spectrum of $\mathrm{C}_{2} \mathrm{~F}_{6}$ in liquid $\mathrm{N}_{2}$ and compare them with the spectrum of $\mathrm{C}_{2} \mathrm{~F}_{6}$ in liquid Xe [8].

\section{Experimental}

The Raman spectrum of liquid $\mathrm{C}_{2} \mathrm{~F}_{6}$ was studied on a Nicolet 6700 spectrometer with a NXR FT-Raman Module. A ND: VO4 laser with a working frequency $v=9398 \mathrm{~cm}^{-1}$ and a peak power of $2.5 \mathrm{~W}$ was used as a light source. The spectroscopic resolution was $1 \mathrm{~cm}^{-1}$. The functional scheme of the cryostat is shown in Fig. 1.

In the standard observation scheme a laser beam from the source (1) goes through the entrance aperture (3) to the parabolic mirror (4) and strikes a sample (2). The sample (2) should be placed in the focus of the parabolic mirror (the focal length $f=2 \mathrm{~cm}$ ). It is very difficult to create a cryostat with linear sizes allowing to place the sample into the mirror focus, so we used a light guide for transferring the focus from the sample cell (12) to the sample place (2).

The cell body (6) is made of brass, which ensures even distribution of temperature all over the cell. The sample temperature is controlled both by nitrogen entering the nitrogen chamber (7) and a heating spiral (8). The temperature is measured by a thermocouple (9). The temperature stability of the experiment reached $2 \mathrm{~K}$.

A clamping flange (10), as well as an indium seal (11) make the fastening of the light guide to the cell body leakproof. One end of the light guide is placed inside the working volume (12), the other in the focus of the parabolic mirror (2).

The light guide diameter is compatible with the size of the entrance aperture (3) in the parabolic mirror (4) and equals $5 \mathrm{~mm}$.

The light guide is $5 \mathrm{~cm}$ long and it serves two purposes: to transfer the focus (2) into the working volume (12) and to choose a temperature gradient. $\mathrm{C}_{2} \mathrm{~F}_{6}$ enters the working volume (12) in a gas phase and next condenses due to temperature reduction.

A spherical mirror for collecting scattered light in the working volume is fastened to the flange (13). The mirror has a curvature radius equal to $1 \mathrm{~cm}$. The working volume is a space in the cryostat filled with investigated substance where scattering occurs.

The experiment was done at a temperature of 178 (5) K. The observed spectrum is presented in Fig. 2. Intensities of the bands observed in the spectrum were determined relative to the strongest $v_{2}$ band, its intensity assigned taken to be 100 relative units.

IR absorption spectra of $\mathrm{C}_{2} \mathrm{~F}_{6}$ in liquid $\mathrm{N}_{2}$ were recorded in the same way as described in paper [9].

It is important to note that when interpreting the Raman and absorption bands we used the numbering of normal modes according to [9].
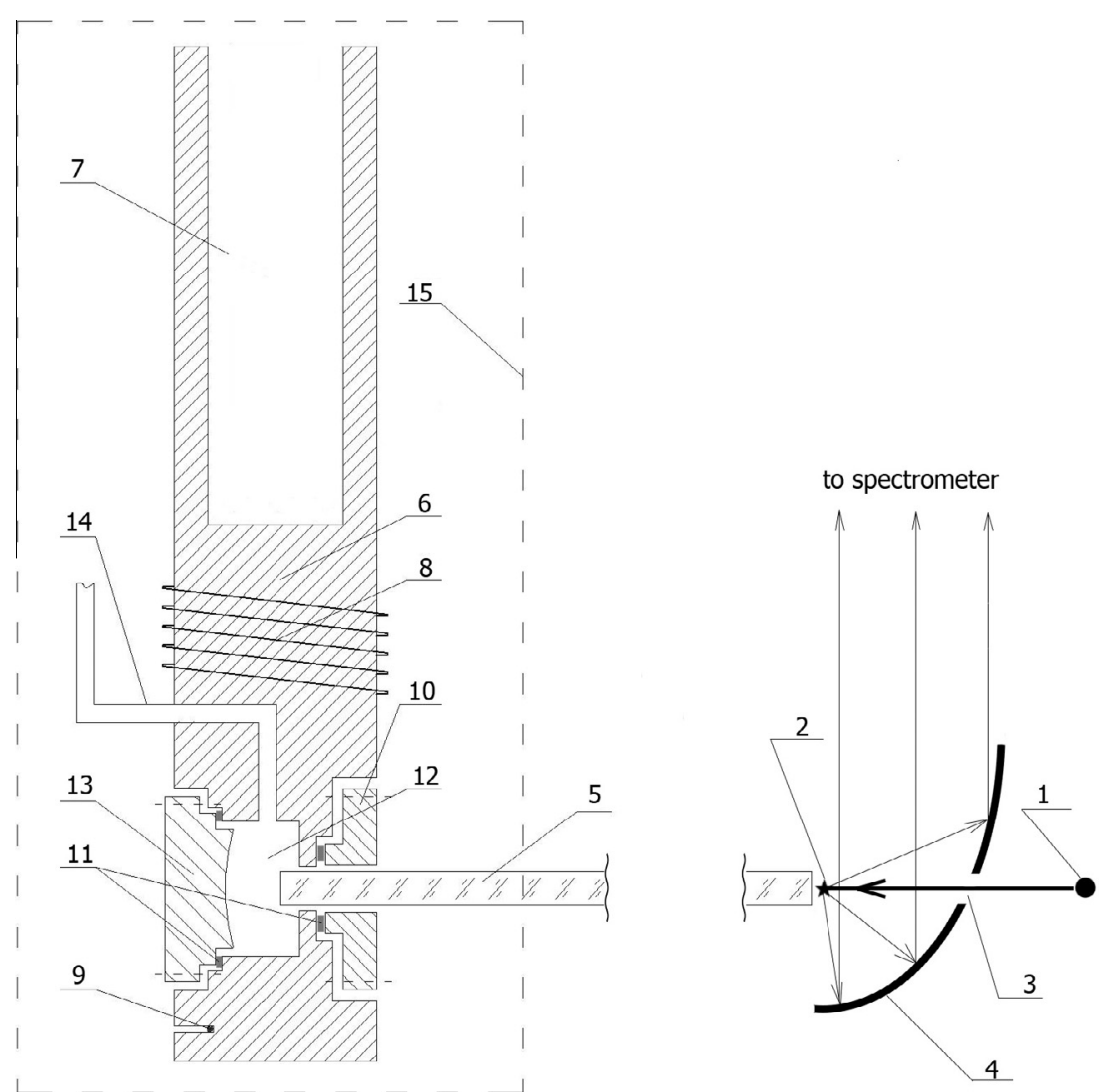

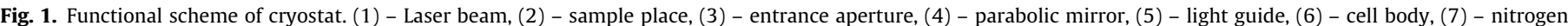

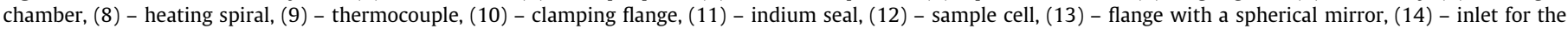
substance, and (15) - heat-insulating cover. 


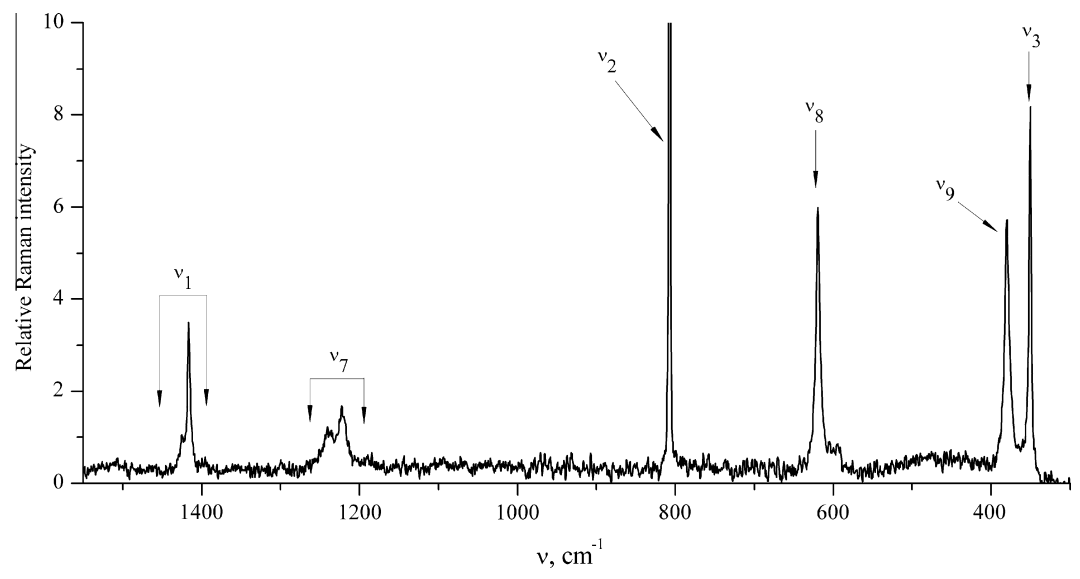

Fig. 2. Fundamental region of the Raman spectrum of liquid $C_{2} F_{6}$ at $T=178$ (2) $\mathrm{K}$.

\section{Results and discussion}

The Raman spectrum parameters of liquid $\mathrm{C}_{2} \mathrm{~F}_{6}$ (frequencies, full widths at half maximum (FWHM), and relative intensities) are presented in Table 1. The analogous data from [5-7] are also presented for comparison. The fundamental frequencies of modes $v_{2}, v_{3}, v_{8}$ and $v_{9}$ are in good agreement with the data of [5-7]. In [5] the band at $655 \mathrm{~cm}^{-1}$ was interpreted as $2 v_{12}$, but in other studies this band was not observed (we have not observed it either).

Table 1 shows that the intensities of the doublet components in the $v_{1}$ spectral region are of the same order of magnitude. Such correlation of intensities of bands of the first and second orders is possible in the case of a Fermi resonance interaction of these states. The Fermi resonance occurs in the case of an identical symmetry of the interacting states; therefore, we consider the doublet in question as a manifestation of Fermi resonance of states $v_{1}\left(A_{1 g}\right)$ and $2 v_{6}\left(A_{1 g}\right)$ in the Raman spectrum of $\mathrm{C}_{2} \mathrm{~F}_{6}$. In this connection we believe the interpretation of this doublet as $v_{1}\left(A_{1 g}\right)$ and $v_{2}+v_{8}\left(E_{g}\right)$ bands in [7] to be incorrect. A doublet with maxima at $1221.9 \mathrm{~cm}^{-1}$ and $1239.7 \mathrm{~cm}^{-1}$ is observed in the spectral region of $v_{7}$ band, the intensities of the doublet components being of the same order (Table 1). The authors of [7] also observed two bands at frequencies $1223 \mathrm{~cm}^{-1}$ and $1242 \mathrm{~cm}^{-1}$ and interpreted them as $v_{7}\left(E_{g}\right)$ and $2 v_{8}\left(E_{g}\right)$, respectively. At the same time the frequency of $v_{6}+v_{11}\left(E_{g}\right)$ is close to that of $v_{7}$ [9]. To illustrate this

Table 1

Experimental frequencies $v_{\mathrm{i}},\left(\mathrm{cm}^{-1}\right)$, FWHM $\left(\mathrm{cm}^{-1}\right)$ and relative intensities of some fundamental and combined Raman bands of liquid $\mathrm{C}_{2} \mathrm{~F}_{6}, T=178 \mathrm{~K}$ (this work) as compared with the literature data.

\begin{tabular}{|c|c|c|c|c|c|c|}
\hline Assignment & $\begin{array}{l}v_{\mathrm{i}} \\
\mathrm{cm}^{-1}\end{array}$ & $\begin{array}{l}\text { FWHM, } \\
\mathrm{cm}^{-1}\end{array}$ & $\begin{array}{l}\text { Raman } \\
\text { intensity, } \\
\text { relative } \\
\text { units }\end{array}$ & $\begin{array}{l}v, \\
\mathrm{~cm}^{-1} \\
{[5]}\end{array}$ & $\begin{array}{l}v, \\
\mathrm{~cm}^{-1} \\
{[6]}\end{array}$ & $\begin{array}{l}v, \\
\mathrm{~cm}^{-1} \\
{[7]}\end{array}$ \\
\hline$v_{3}, A_{1 g}$ & 350.4 & 3.2 & 20.2 & 349 & 348 & 351 \\
\hline$v_{9}, E_{g}$ & 380.2 & 7.3 & 30.8 & 380 & 372 & 381 \\
\hline$v_{8}, E_{g}$ & 619.4 & 5.7 & 29.0 & 620 & 619 & 620 \\
\hline $2 v_{12}, A_{1 g}, E_{g}$ & - & - & - & 655 & - & - \\
\hline$v_{2}, A_{1 g}$ & 807.5 & 1.2 & 100 & 809 & 807.4 & 807 \\
\hline$\left(v_{7}\right.$ & 1221.9 & 14 & 13.9 & \multirow[t]{2}{*}{1237} & \multirow[t]{2}{*}{1250} & 1223 \\
\hline$\left\{\begin{array}{l}2 v_{8} \\
v_{6}+v_{11}\end{array}, E_{g}\right.$ & 1239.7 & 11 & 9.0 & & & $1242^{(1)}$ \\
\hline$\left\{v_{1} \quad A_{1 g}\right.$ & 1416.3 & 4.3 & 17.6 & \multirow[t]{2}{*}{1420} & \multirow[t]{2}{*}{1417} & 1417 \\
\hline $22 v_{6}, A_{1 g}$ & 1425.0 & 7.2 & 6.2 & & & $1426^{(2)}$ \\
\hline
\end{tabular}

Notes: 1 - the authors of [7] interpreted this band as $\left(2 v_{8}, E_{g}\right), 2$ - the authors of [7] interpreted this band as $\left(v_{2}+v_{8}, E_{g}\right)$. point, let us consider the sum of appropriate fundamental frequencies: $\left(v_{6}+v_{11}\right)=714+522.5=1236.5 \mathrm{~cm}^{-1} ; 2 v_{8}=2\left(v_{8}\right)=$ $2.619 .5=1239 \mathrm{~cm}^{-1} ; v_{7}=1237 \mathrm{~cm}^{-1}$ (the frequencies are taken from [9]). Consequently, it is necessary to consider resonance interaction of the three $\left(E_{g}\right)$ states $v_{7},\left(v_{6}+v_{11}\right)$ and $2 v_{8}$ through cubic constants of potential energy $K_{67,11}$ and $K_{788}$. In the present study we determine the cubic constants $K_{i j k}$ of intramolecular potential function $V(q)$ represented by a power series expansion in products of dimensionless normal molecular coordinates $q$ [10]: $V(q)=(1 / 2) \sum_{i} \omega_{i} q_{i}^{2}+\sum_{i j k} K_{i j k} q_{i} q_{j} q_{k}+\cdots$.

The results of measurements of frequencies and intensities of Fermi multiplets in the IR spectra of $\mathrm{C}_{2} \mathrm{~F}_{6}$ in liquid $\mathrm{N}_{2}$ are presented in Table 2. The table demonstrates manifestation of the same resonances of all observed states combined with $v_{1}$ and $v_{7}$ vibrations.

Let us consider the Fermi doublets in the $v_{1}$ and $v_{7}$ spectral regions in more detail (Fig. 3a and b). In both spectral regions one can observe two bands with close intensities, the components of each doublet being described by Lorentz contours, which makes it possible to determine the quantitative characteristics of Fermi resonance.

Once the experimental values of splitting $(\chi)$ and relative intensities of the doublet $(R)$ are obtained, one can define resonance detuning $\Delta=\chi(1-R) /(1+R)$ and interaction matrix elements of states $W=\sqrt{\chi^{2}-\Delta^{2}} / 2$.

Thus, the $v_{1} \sim 2 v_{6}\left(A_{1 g}\right)$ resonance appears in all states combined with $v_{1}$ in IR absorption spectra (Fig. 4).

Table 2

Experimental frequencies $v_{\mathrm{i}}\left(\mathrm{cm}^{-1}\right)$, FWHM $\left(\mathrm{cm}^{-1}\right)$, and intensities of combination absorption bands (A) of $\mathrm{C}_{2} \mathrm{~F}_{6}$ in liquid nitrogen, $T=77 \mathrm{~K}$.

\begin{tabular}{|c|c|c|c|}
\hline Assignment & $v_{\mathrm{i}}, \mathrm{cm}^{-1}$ & FWHM, $\mathrm{cm}^{-1}$ & $\mathrm{~A}, \mathrm{~km} / \mathrm{mol}$ \\
\hline$\left\{\begin{array}{l}v_{7}+v_{12} \\
v_{6}+v_{11}+v_{12} \\
2 v_{8}+v_{12}\end{array}\right.$ & $\begin{array}{l}1442.0 \\
1457.4\end{array}$ & $\begin{array}{l}3.6 \\
3.6\end{array}$ & $\begin{array}{l}1.3 \\
0.8\end{array}$ \\
\hline $\begin{array}{l}\left\{\begin{array}{l}v_{1}+v_{12} \\
2 v_{6}+v_{12}\end{array}\right. \\
\left\{\begin{array}{l}v_{1}+v_{6} \\
3 v_{6}\end{array}\right.\end{array}$ & $\begin{array}{l}1632.9 \\
1642.2 \\
2126.3 \\
2139.7\end{array}$ & $\begin{array}{l}2.3 \\
2.5 \\
1.5 \\
1.5\end{array}$ & $\begin{array}{l}0.8 \\
0.2 \\
0.065 \\
0.045\end{array}$ \\
\hline$\left\{\begin{array}{l}v_{7}+v_{10} \\
2 v_{8}+v_{10} \\
v_{6}+v_{10}+v_{11}\end{array} A_{2 u}\right.$ & $\begin{array}{l}2455.3 \\
2477.7\end{array}$ & $\begin{array}{l}4.5 \\
5.1\end{array}$ & $\begin{array}{l}0.6 \\
0.3\end{array}$ \\
\hline$\left\{\begin{array}{l}v_{7}+v_{10} \\
2 v_{8}+v_{10} \\
v_{6}+v_{10}+v_{11}\end{array} E_{u}\right.$ & $\begin{array}{l}2465.5 \\
2482.2\end{array}$ & $\begin{array}{l}5.0 \\
6.0\end{array}$ & $\begin{array}{l}1.9 \\
3.1\end{array}$ \\
\hline$\left\{\begin{array}{l}v_{1}+v_{10} \\
2 v_{6}+v_{10}\end{array}\right.$ & $\begin{array}{l}2657.8 \\
2665.7\end{array}$ & $\begin{array}{l}2.9 \\
2.5\end{array}$ & $\begin{array}{l}1.65 \\
1.45\end{array}$ \\
\hline
\end{tabular}




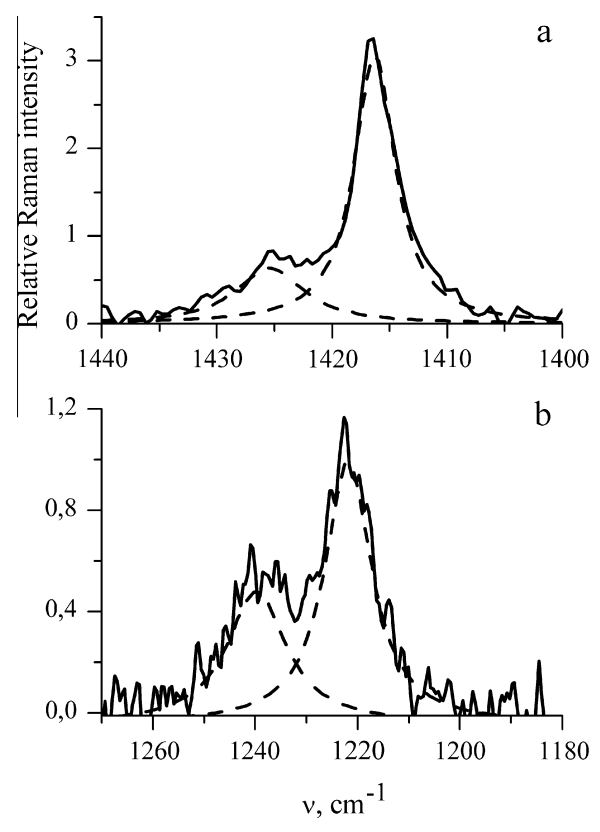

Fig. 3. Raman spectrum of liquid $\mathrm{C}_{2} \mathrm{~F}_{6}(T=178 \mathrm{~K})$ in spectral regions of $v_{1}$ band (a) and $v_{7}$ band (b). The dashed curve shows the Lorentz contours describing the band shapes.

Table 3 presents the results of processing of the experimental data obtained from the Raman spectrum of liquid $\mathrm{C}_{2} \mathrm{~F}_{6}$ and IR spectra $\mathrm{C}_{2} \mathrm{~F}_{6}$ in liquid $\mathrm{N}_{2}$ and in liquid Xe [8] in the spectral region of the $v_{1}$ band and those containing $v_{1}$.

It is evident that the values of $\chi$ and $R$ considerably depend on the experimental conditions. At the same time the values of $W$
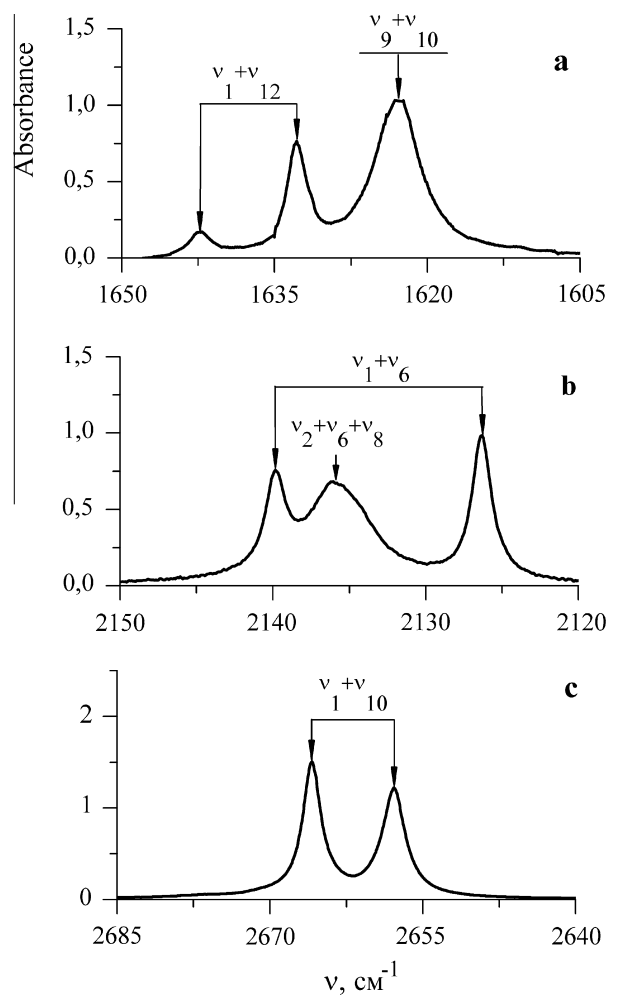

Fig. 4. Absorption spectra of $\mathrm{C}_{2} \mathrm{~F}_{6}$ solution in liquid $\mathrm{N}_{2}(T=77 \mathrm{~K}, l=2.5 \mathrm{~cm}$ $C=1.2 * 10^{-5} \mathrm{~mol} / \mathrm{cm}^{3}$ ) in $v_{1}+v_{12} \sim 2 v_{6}+v_{12} \quad(a), \quad v_{1}+v_{6} \sim 3 v_{6} \quad$ (b) and $v_{1}+v_{10} \sim 2 v_{6}+v_{10}$ (c) spectral regions.
Table 3

Experimental frequencies $\left(v_{\mathrm{i}}\right)$ and parameters of Fermi resonance $v_{1} \sim 2 v_{6}$ obtained from Raman spectra of liquid $\mathrm{C}_{2} \mathrm{~F}_{6}(T=178 \mathrm{~K})$ and solutions of $\mathrm{C}_{2} \mathrm{~F}_{6}$ in liquid Xe $(163 \mathrm{~K})[8]$ and $\mathrm{N}_{2}(T=77 \mathrm{~K})$ : splitting $(\chi)$, relative intensities of doublet $(R)$, interaction matrix elements of states $(W)$ and resonance detuning $(\Delta)$.

\begin{tabular}{|c|c|c|c|c|c|c|}
\hline Resonance & System, activity & $\begin{array}{l}v_{\mathrm{i}}, \\
\mathrm{cm}^{-1}\end{array}$ & $\begin{array}{l}\chi, \\
\mathrm{cm}^{-1}\end{array}$ & $R$ & $\begin{array}{l}W, \\
\mathrm{~cm}^{-1}\end{array}$ & $\begin{array}{l}\Delta, \\
\mathrm{cm}^{-1}\end{array}$ \\
\hline $\begin{array}{l}v_{1} \\
2 v_{6}\end{array}$ & $\begin{array}{l}\text { Liq. } \mathrm{C}_{2} \mathrm{~F}_{6} \text {, } \\
\text { Raman }\end{array}$ & $\begin{array}{l}1417.5 \\
1424.8\end{array}$ & $8.7(2)$ & 0.35 & $3.8(1)$ & $4.2(5)$ \\
\hline $\begin{array}{l}v_{1}+v_{10} \\
2 v_{6}+v_{10}\end{array}$ & $\begin{array}{l}\mathrm{C}_{2} \mathrm{~F}_{6} / \text { Liq. Xe [8], } \\
\text { IR } \\
\mathrm{C}_{2} \mathrm{~F}_{6} / \text { Liq. } \mathrm{N}_{2} \\
\text { IR }\end{array}$ & $\begin{array}{l}2651.0 \\
2659.8 \\
2657.8 \\
2665.7\end{array}$ & $\begin{array}{l}8.8(2) \\
7.9(2)\end{array}$ & $\begin{array}{l}0.60 \\
0.90\end{array}$ & $\begin{array}{l}4.2(1) \\
3.9(1)\end{array}$ & $\begin{array}{l}-2.2 \\
(4) \\
0.4(4)\end{array}$ \\
\hline $\begin{array}{l}v_{1}+v_{6} \\
3 v_{6}\end{array}$ & $\begin{array}{l}\mathrm{C}_{2} \mathrm{~F}_{6} / \text { Liq. Xe [8] } \\
\text { IR } \\
\mathrm{C}_{2} \mathrm{~F}_{6} / \text { Liq. } \mathrm{N}_{2} \\
\text { IR }\end{array}$ & $\begin{array}{l}2123.0 \\
2136.6 \\
2126.3 \\
2139.7\end{array}$ & $\begin{array}{l}13.6 \\
(2) \\
13.4 \\
(2)\end{array}$ & $\begin{array}{l}0.57 \\
0.67\end{array}$ & $6.4(1)$ & $\begin{array}{l}3.8(7) \\
3.7(5)\end{array}$ \\
\hline$\left\{\begin{array}{l}v_{1}+v_{12} \\
2 v_{6}+v_{12}\end{array}\right.$ & $\begin{array}{l}\mathrm{C}_{2} \mathrm{~F}_{6} / \text { Liq. } \mathrm{N}_{2} \\
\text { IR }\end{array}$ & $\begin{array}{l}1632.9 \\
1642.2\end{array}$ & $9.3(2)$ & 0.25 & $3.7(2)$ & $5.6(5)$ \\
\hline
\end{tabular}

coincide to within the experimental error, except for the $v_{1}+v_{6}$ spectral region. The value of $W$ varies with the quantum numbers of interacting states: $W\left(v_{1} \sim 2 v_{6}\right)=K_{166} / 2, W\left(v_{1}+v_{6} \sim 3 v_{6}\right)=$ $\sqrt{3} K_{166} / 2$. Combined processing of data on all the doublets gives the value of the cubic constant $K_{166}=7.7$ (2) $\mathrm{cm}^{-1}$.

In the $v_{7}$ spectral region interaction of three vibrational states (a threefold resonance) should be taken into account. The secular equation can be presented as follows:

$\left|\begin{array}{ccc}E_{1}^{0}-\lambda & W_{1} & W_{2} \\ W_{1} & E_{2}^{0}-\lambda & 0 \\ W_{2} & 0 & E_{3}^{0}-\lambda\end{array}\right|=0$

where $E_{i}^{0}$ represents the energy values unperturbed by resonance; $W_{1}=K_{788} / \sqrt{2} ; W_{2}=K_{67,11} / 2 \sqrt{2}$. The matrix element of interactions of vibrational states $2 v_{8}$ with $v_{6}+v_{11}$ is too small to be taken into consideration.

Such threefold resonances were discussed in more detail in [11]. The paper [11] shows that a threefold resonance appears in the form of a doublet in the case where the interaction matrix elements are larger than the splitting of unperturbed levels $E_{2}$ $\left(v_{6}+v_{11}\right)$ and $E_{3}\left(2 v_{8}\right)$.

In such case it is only possible to obtain a value of an "effective» matrix element of interaction $W_{\text {eff. }}=\sqrt{W_{1}^{2}+W_{2}^{2}}$ from experimental data, the average of the values makes $W_{\text {eff }}=8.5(5) \mathrm{cm}^{-1}$. We should also note that the bands corresponding to vibrations combined with $v_{7}$ have a doublet structure both in the Raman and IR spectra (Figs. 3a and 5).

Table 4 presents the results of experimental data processing obtained from the Raman spectrum of liquid $\mathrm{C}_{2} \mathrm{~F}_{6}$ and IR spectra $\mathrm{C}_{2} \mathrm{~F}_{6}$ in liquid $\mathrm{N}_{2}$ and in liquid $\mathrm{Xe}$ [8] in $\mathrm{v}_{7}$ spectral region and those containing $\mathrm{v}_{7}$.

To illustrate the correctness of these interpretations, the optimized geometry and vibrational frequencies were calculated in the ab initio Møller-Plesset second-order (MP2) frozen core approximation [12] with the Pople-type 6-311++G(df,pd) basis set by the Gaussian 09 package [13]. The anharmonic frequencies and the cubic anharmonicity constants were calculated using the option "anharmonic".

The ab initio calculation of the molecule $\mathrm{C}_{2} \mathrm{~F}_{6}$ gives a value of the cubic constant $K_{166}=6.6 \mathrm{~cm}^{-1}$, the corresponding experimental value is $K_{166}=7.7(2) \mathrm{cm}^{-1}$. 


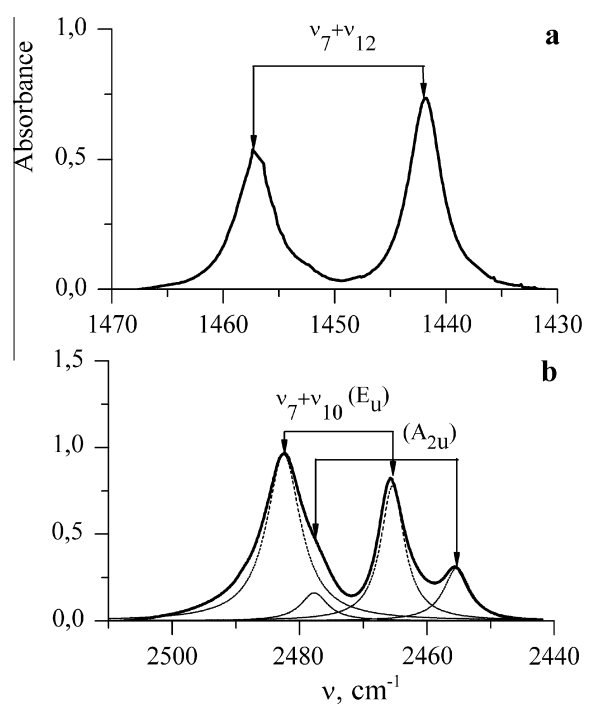

Fig. 5. Absorption spectra of $\mathrm{C}_{2} \mathrm{~F}_{6}$ solution in liquid $\mathrm{N}_{2}(T=77 \mathrm{~K}, l=2.5 \mathrm{~cm}$, $C=1.2 * 10^{-5} \mathrm{~mol} / \mathrm{cm}^{3}$ ) in the $v_{7}+v_{12} \sim 2 v_{8}+v_{12} \sim v_{6}+v_{11}+v_{12} \quad$ (a), $\quad v_{7}$ $+v_{10} \sim 2 v_{8}+v_{10} \sim v_{6}+v_{10}+v_{11}$ (b) spectral regions. The dotted lines represent Lorentz contours describing the multiplet components. In the region of $v_{7}+v_{10}$ vibration (Fig. 5b) there are two doublets (one having symmetry $A_{2 u}$ and the other $-E_{u}$ ).

\section{Table 4}

Experimental frequencies $\left(v_{\mathrm{i}}\right)$ and parameters of Fermi resonance $v_{7} \sim 2 v_{8} \sim v_{6}+v_{11}$ obtained from Raman spectra of liquid $C_{2} F_{6}(T=178 \mathrm{~K})$ and solutions of $C_{2} F_{6}$ in liquid Xe $(163 \mathrm{~K})$ [8] and $\mathrm{N}_{2}(T=77 \mathrm{~K})$ : splitting $(\chi)$, relative intensities of doublet $(R)$, effective interaction matrix elements of states $\left(W_{\text {eff }}\right)$ and resonance detuning $(\boldsymbol{A})$.

\begin{tabular}{|c|c|c|c|c|c|c|}
\hline Resonance & System, activity & $\begin{array}{l}v_{\mathrm{i}}, \\
\mathrm{cm}^{-1}\end{array}$ & $\begin{array}{l}\chi, \\
\mathrm{cm}^{-1}\end{array}$ & $R$ & $\begin{array}{l}\Delta, \\
\mathrm{cm}^{-1}\end{array}$ & $\begin{array}{l}W_{\text {eff }} \\
\mathrm{cm}^{-1}\end{array}$ \\
\hline$\left\{\begin{array}{l}v_{7} \\
v_{6}+v_{11} \\
2 v_{8}\end{array}\right.$ & $\begin{array}{l}\text { Liq. } \mathrm{C}_{2} \mathrm{~F}_{6} \text {, } \\
\text { Raman }\end{array}$ & $\begin{array}{l}1221.9 \\
1239.7\end{array}$ & 17.8 & $\begin{array}{l}0.6 \\
(1)\end{array}$ & $9(1)$ & $\begin{array}{l}8.6 \\
(4)\end{array}$ \\
\hline$\left\{\begin{array}{l}v_{7}+v_{12} \\
v_{6}+v_{11}+v_{12} \\
2 v_{8}+v_{12}\end{array}\right.$ & $\begin{array}{l}\mathrm{C}_{2} \mathrm{~F}_{6} / \text { Liq. Xe [8], } \\
\text { IR } \\
\mathrm{C}_{2} \mathrm{~F}_{6} / \text { Liq. } \mathrm{N}_{2} \\
\text { IR }\end{array}$ & $\begin{array}{l}1440.0 \\
1456.0 \\
1442.0 \\
1457.4\end{array}$ & $\begin{array}{l}16.0 \\
15.4\end{array}$ & $\begin{array}{l}0.75 \\
(5) \\
0.8 \\
(1)\end{array}$ & $\begin{array}{l}2.3 \\
(5) \\
2.2 \\
(9)\end{array}$ & $\begin{array}{l}7.9 \\
(1) \\
7.6 \\
(1)\end{array}$ \\
\hline$\left\{\begin{array}{l}v_{7}+v_{10} \\
v_{6}+v_{10}+v_{11}, A_{2 u} \\
2 v_{8}+v_{10}\end{array}\right.$ & $\begin{array}{l}\mathrm{C}_{2} \mathrm{~F}_{6} / \text { Liq. } \mathrm{N}_{2} \\
\text { IR }\end{array}$ & $\begin{array}{l}2455.3 \\
2477.7\end{array}$ & 22.4 & $\begin{array}{l}0.50 \\
(5)\end{array}$ & $8(1)$ & $\begin{array}{l}10.6 \\
(2)\end{array}$ \\
\hline$\left\{\begin{array}{l}v_{7}+v_{10} \\
v_{6}+v_{10}+v_{11}, E_{u} \\
2 v_{8}+v_{10}\end{array}\right.$ & $\begin{array}{l}\mathrm{C}_{2} \mathrm{~F}_{6} / \text { Liq. Xe [8], } \\
\text { IR } \\
\mathrm{C}_{2} \mathrm{~F}_{6} / \text { Liq. } \mathrm{N}_{2} \\
\text { IR }\end{array}$ & $\begin{array}{l}2458.9 \\
2475.4 \\
2465.5 \\
2482.2\end{array}$ & 16.5 & $\begin{array}{l}0.60 \\
(5) \\
0.60 \\
(5)\end{array}$ & $\begin{array}{l}4.1 \\
(7) \\
4.2 \\
(7)\end{array}$ & $\begin{array}{l}8.0 \\
(1) \\
8.1 \\
(1)\end{array}$ \\
\hline
\end{tabular}

The ab initio calculation gives the values of cubic constants $K_{67,11}=-18.2 \mathrm{~cm}^{-1}$ and $K_{788}=5.4 \mathrm{~cm}^{-1}$, which enables us to determine the corresponding matrix elements of interaction $v_{7} \sim\left(2 v_{8}\right) \sim\left(v_{6}+v_{11}\right)$ states as $W_{1}=K_{788} / \sqrt{2}=3.8 \mathrm{~cm}^{-1}, W_{2}=$ $K_{67,11} / 2 \sqrt{2}=6.4 \mathrm{~cm}^{-1}$. Thus, according to the calculation, the value of the "effective" matrix element of interaction is $W_{\text {eff }}=7.4 \mathrm{~cm}^{-1}$, the corresponding experimental value is $W_{\text {eff }}=8.5(5) \mathrm{cm}^{-1}$. It is evident that the experimental and calculated values of "effective" matrix elements for a threefold resonance $v_{7} \sim\left(2 v_{8}\right) \sim\left(v_{6}+v_{11}\right)$ are in good accordance with each other. We note that the value of $W_{\text {eff }}$ is close to $W_{2}$ and the shape of the spectrum is determined, above all, by the resonance interaction of $v_{7}$ and $\left(v_{6}+v_{11}\right)$ states.

\section{Conclusions}

In this paper we described the doublets in the Raman spectrum of liquid $C_{2} F_{6}$ in the spectral regions of $v_{1}$ and $v_{7}$ bands. The corresponding resonances of high vibrational states are observed in absorption spectra of $\mathrm{C}_{2} \mathrm{~F}_{6}$ in liquid $\mathrm{N}_{2}$. The calculated cubic anharmonicity parameters determine the form of molecular vibrational spectra, both in Raman and IR regions. For a proper interpretation of vibrational spectra it is necessary to consider interactions of all the three states $v_{7} \sim\left(2 v_{8}\right) \sim\left(v_{6}+v_{11}\right)$ (all of them have the $E_{g}$ symmetry).

\section{Acknowledgments}

This work was supported by the Russian Foundation for Basic Research, projects Nos. 14-03-00716 and 12-03-31113 mol_a. The spectroscopic measurements were partly performed on the apparatus of the Resource Center Geomodel of Saint-Petersburg State University. The calculations have been performed using the computer resources of the Resource Centre of SPbGU (http://cc.spbu.ru). The authors thank Drs. A.I. Baskin and S.M. Melikova for assistance and helpful discussion.

\section{References}

[1] D.R. Worton, W.T. Sturges, L.K. Gohar, K.P. Shine, P. Martinerie, D.E. Oram, S.P. Humphrey, P. Begley, L. Gunn, J.-M. Barnola, J. Schwander, R. Mulvaney, Environ. Sci. Technol. 41 (2007) 2184, http://dx.doi.org/10.1021/es061710t.

[2] I. Bravo, A. Aranda, M.D. Hurley, G. Marston, D.R. Nutt, K.P. Shine, K. Smith, T.J. Wallington, J. Geophys. Res. 115 (2010) D24317, http://dx.doi.org/10.1029/ 2010JD014771.

[3] V. Kochikov, G.M. Kuramshina, A.V. Stepanova, A.G. Yagola, Numer. Methods Program. 5 (2004) 281.

[4] Y.N. Panchenko, G.R. De Mare, J. Mol. Struct. 611 (2002) 147, http://dx.doi.org/ 10.1016/S0022-2860(02)00063-7.

[5] D.N. Rank, E.L. Pace, J. Chem. Phys. 15 (1) (1947) 39, http://dx.doi.org/10.1063/ 1.1746283.

[6] J.R. Nielsen, C.W. Gullikson, J. Chem. Phys. 21 (1) (1953) 1416, http:// dx.doi.org/10.1063/1.1699254.

[7] A. Lewis, E.L. Pace, J. Chem. Phys. 58 (9) (1973) 3661, http://dx.doi.org/ $10.1063 / 1.1679716$.

[8] O.S. Golubkova, V.N. Bocharov, A.P. Burtsev, D.N. Shchepkin, Opt. Spectr. 111 (2011) 357, http://dx.doi.org/10.1134/S0030400X11090098.

[9] O.S. Golubkova, T.D. Kolomiitsova, D.N. Shchepkin, K.G. Tokhadze, J. Mol Struct. 1054-1055 (2013) 12, http://dx.doi.org/10.1016/j.molstruc.2013. 09.012.

[10] T. Kolomiitsova, D. Shchepkin, Vibration spectra of polyatomic molecules, in: R.J.H. Clark, R.E. Hester (Eds.), Molecular Cryospectroscopy, Advances in Spectroscopy, vol. 23, Wiley, Chichester, 1995, p. 92.

[11] T. Kolomiitsova, D. Shchepkin, Vibration spectra of polyatomic molecules, in: R.J.H. Clark, R.E. Hester (Eds.), Molecular Cryospectroscopy, Advances in Spectroscopy, vol. 23, Wiley, Chichester, 1995, pp. 111-115.

[12] C. Møller, M.S. Plesset, Phys. Rev. 46 (1934) 618, http://dx.doi.org/10.1103/ PhysRev.46.618.

[13] M.J. Frisch, G.W. Trucks, H.B. Schlegel, G.E. Scuseria, M.A. Robb, J.R. Cheeseman, G. Scalmani, V. Barone, B. Mennucci, G.A. Petersson, H. Nakatsuji, M. Caricato, X. Li, H.P. Hratchian, A.F. Izmaylov, J. Bloino, G. Zheng, J.L. Sonnenberg, M. Hada, M. Ehara, K. Toyota, R. Fukuda, J. Hasegawa, M. Ishida, T. Nakajima, Y. Honda, O. Kitao, H. Nakai, T. Vreven, J.A. Montgomery, Jr., J.E. Peralta, F. Ogliaro, M. Bearpark, J.J. Heyd, E. Brothers, K.N. Kudin, V.N. Staroverov, T. Keith, R. Kobayashi, J. Normand, K. Raghavachari, A. Rendell, J.C. Burant, S. S. Iyengar, J. Tomasi, M. Cossi, N. Rega, J.M. Millam, M. Klene, J.E. Knox, J.B. Cross, V. Bakken, C. Adamo, J. Jaramillo, R. Gomperts, R.E. Stratmann, O. Yazyev, A.J. Austin, R. Cammi, C. Pomelli, J.W. Ochterski, R.L. Martin, K. Morokuma, V.G. Zakrzewski, G.A. Voth, P. Salvador, J.J. Dannenberg, S. Dapprich, A.D. Daniels, O. Farkas, J.B. Foresman, J.V. Ortiz, J. Cioslowski, D.J. Fox, Gaussian 09, Revision C.01. Gaussian Inc., Wallingford CT, 2010. 